\title{
Can left ventricular function parameters be determined within half of the time with MRI?
}

\author{
Leo H. B. Baur
}

Received: 30 June 2007 / Accepted: 4 July 2007 / Published online: 25 July 2007

(C) Springer Science+Business Media B.V. 2007

Accurate determination of left ventricular mass and left ventricular systolic volume and function is important for assessment of prognosis and therapeutic options in patients with hypertensive heart disease, coronary heart disease and congestive heart failure $[1,2]$.

In patients with hypertension, left ventricular hypertrophy increases the relative risk of mortality by twofold in those patients who also have coronary artery disease and by fourfold in those patients with normal coronary arteries [3]. Because of the low cost, M-mode echocardiography is the most widely used method to determine left ventricular mass [4]. However, there is considerable variability for repeated measurements. Two-dimensional and 3-dimensional echocardiography is more used for determination of left ventricular volumes and left ventricular ejection fraction, with an excellent intra-observer variability but worse inter-observer variability [5]. Additionally, not in all patients high quality images can be obtained, which permit precise assessment of left ventricular volumes and function. Because of its high spatial and temporal resolution, MRI is the best technique for assessment of right and left ventricular function. For determination of left ventricular function one can

L. H. B. Baur $(\bowtie)$

Department of Cardiology, Atrium Medical Centre

Parkstad, Henri Dunantstreet 5, 6401 CX Heerlen,

The Netherlands

e-mail: 1br01@atriummc.nl either use the Simpson's rule or the area-length method. With the Simpson's rule left ventricular volumes are calculated by summing the endocardial area within multiple short axis slices from base to apex of the heart and multiplying each area by the slice thickness [6]. Left ventricular volumes and left ventricular mass using this technique have been validated with cast measurements and cadaver studies and show an excellent correlation. Intra- and interobserver variability of the measurements of left ventricular volume, ejection fraction and left ventricular mass are very low [7, 8]. Because of this high reproducibility, in clinical trials, only limited number of patients are needed to detect a change of left ventricular volume, ejection fraction or left ventricular mass. Studies, that use MR, require sample sizes that are 80-90\% smaller than other imaging methods [9]. For calculation left ventricular mass endocardial and epicardial contours have to be drawn from base to apex and multiplied by slice thickness [10]. Manually, tracing of all contours is cumbersome and time consuming. Also with automated contour detection using commercially available software correct analysis remains time consuming. In this issue of the International Journal of Cardiac Imaging, Lubbers et al. demonstrate, that by tracing every second slice decreases accuracy for left ventricular ejection fraction with only $1.7 \%$ and for left ventricular mass with $4.1 \%$. For left ventricular volume one has to be aware, however that tracing half of the slices gives half the accuracy compared to true volume. In clinical studies, 
this could imply the need of more patients for comparison. For normal patient care the method suggested by Lubbers satisfies completely and could become the standard procedure for measurement of left ventricular mass, volume and function. However, in clinical studies one can better rely on the better accuracy of tracing all slices.

\section{References}

1. Levy D, Garrison RJ, Savage DD, Kannel WB, Castelli WP (1990) Prognostic implications of echocardiographically determined left ventricular mass in the Framingham heart study. N Engl J Med 322:1561-1566

2. White HD, Norris RM, Brown MA, Brandt PWT, Whitlock RML, Wild CJ (1987) Left ventricular endsystolic volume as the major determinant of survival after recovery from myocardial infarction. Circulation 76:44-51

3. Ghali JK, Liao Y, Simmons B, Castaner A, Cao G, Cooper RS (1990) The prognostic role of left ventricular hypertrophy in patients with systemic hypertension and marked left ventricular wall thickening. Am J Cardiol 65:874-881

4. Devereux RB, Reichek N (1997) Echocardiographic determination of left ventricular mass in man: anatomic validation of the method. Circulation 55:613-618

5. Baur LHB, Schipperheyn JJ, van der Velde EA, Reiber JHC, van Dijkman PRM, Gerrittsen G, van Eck-Smit B,
Voogd PJ, van der Wall EE, Bruschke AVG (1996) Reproducibility of left ventricular size, shape and mass with echocardiography, magnetic resonance imaging and radionuclide angiography in patients with anterior wall infarction: a plea for core laboratories. Int J Card Imaging 12:233-240

6. Longmore DB, Klipstein RH, Underwood SR, Firmin DN, Hounsfield GN, Watanabe M, Bland C, Fox K, PooleWilson PA, Rees RS et al (1985) Dimensional accuracy of magnetic resonance in studies of the heart. Lancet 1(8442):1360-1362

7. Pattynama PM, Lamb HJ, Van der Velde EA, van der Wall EE, de Roos A (1993) Left ventricular measurements with cine and spin echo MR imaging: a study of reproducibility with variance component analysis. Radiology 187:261-268

8. Matheijssen NAA, Baur LHB, Reiber JHC, van der Velde EA, van Dijkman PRM, van der Geest RJ, de Roos A, van der Wall EE (1996) Assessment of left ventricular volume and mass by short-axis cine magnetic resonance imaging in patients with anterior myocardial infarction: intra- and inter-observer variability on endocardial and epicardial contours. Int J Card Imaging 12:11-19

9. Meyer SL, Curry GC, Donsky MS, Twieg DB, Parkey RW, Willerson JT (1976) Influence of dobutamine on hemodynamics and coronary blood flow in patients with and without coronary artery disease. Am J Cardiol 38:103-108

10. Lorenz CH, Walker ES, Morgan VL, Klein SS, Graham TP (1999) Normal human right and left ventricular mass, systolic function and gender differences by cine magnetic resonance imaging. J Cardiovasc Magn Reson 1:7-21 